\title{
Às voltas com as formas de cortesia em galego atual
}

\section{Around Honorifics in Contemporary Galician}

\author{
XAVIER FríAs CONDE \\ UNED \\ xfrias@flog.uned.es \\ Recibido: enero de 2018. Aceptado: febrero de 2018
}

\begin{abstract}
Resumo: A maioria dos manuais de língua galega passam na ponta dos pés ao se referir às formas de tratamento. Limitam-se a assinalar a diferença entre $t u /$ ti por um lado e vostê por outro. As referências a outras formas ainda vivas, embora moribundas no idioma, são muito escassas. Por isso, neste artigo analisamos todas essas formas (vós de cortesia, ele/a, o tio/a tia) e mediante um sistema de etiquetagem comparamos as suas caraterísticas, principalmente a dêixis do tratamento. Aliás, tentamos estabelecer qual a sua origem e o seu desenvolvimento, também do ponto de vista estrutural, visando estabelecer um quadro completo de quais as formas de cortesia em galego.
\end{abstract}

Palavras clave: Formas de cortesia, pronomes de cortesia, galego, etiquetagem, referência, paradigma.

\begin{abstract}
Most handbooks dealing with the Galician language prefer to tiptoe around the so-called honorifics. They merely mark out the differences between $t u / t i(« t h o u »)$ and vostê (formal «you»). The references to other forms still alive, yetendangered, are quite rare. Therefore the present study aims to analyse all these forms (courtesy vós, ele/a, o tio/a tia) and compare their features by means of a tagging system, mainly focusing on the deixis of courtesy. Moreover, this study describes the origin and latter development of such forms, also from a structural point of view, trying to set a complete framework of which are the actual Galician courtesy forms.
\end{abstract}

Key words: Honorifics, courtesy pronouns, Galician, tagging, reference, paradigm. 


\section{INTRODUÇÃO}

Há algum tempo fizemos um percurso pelas formas de tratamento no portugalego atual (Frias 2011), comparando o sistema de pronomes de cortesia em galego, português europeu e brasileiro. Recentemente demos ao prelo um estudo de caráter mais geral em que estabelecíamos um quadro metodológico para estudar as ditas formas por meio de um sistema de etiquetagem (Frias \&Uruburu 2017). Neste livro, estabelecíamos três eixos para a abordagemdo estudo das formas de tratamento.

Em primeiro lugar, fala-se nos graus $\left(\mathrm{G}^{\circ}{ }^{\circ}\right)$, que vão do mais formal ao mais familiar; em segundo lugar, fala-se do paradigma da forma verbal (se é segunda ou terceira pessoa, marcada como ПI); finalmente, a referência (R), que no caso que nos ocupa será sempre segunda pessoa. Assim, ao estabelecermos quais as diferenças entre $t u$ e vostê $\hat{e}^{l}$ em galego, baseadas no conceito de dêixis social cunhado por Calvo (2012: 140): temos uma primeira comparação muito elementar:

\begin{tabular}{|l|c|c|}
\hline & $t u$ & vostê \\
\hline Grau (dêixis) & {$[-$ formal $]$} & {$[+$ formal $]$} \\
\hline$\Pi$ & $2 \mathrm{PS}$ & $3 \mathrm{PS}$ \\
\hline $\mathrm{R}$ & $2 \mathrm{PS}$ & 2PS \\
\hline
\end{tabular}

Porém, no galego falado existem ainda mais fórmulas, algumas intermédias, como o ele a meio caminho entre o tu e o vostê ou mesmo sintagmáticas, como o tio/a tia, comum com o português rural, das quais se fala pouco. De facto são sistemas paralelos que coabitam e, em muitos casos, com algum dos seus elementos em decadência.

\section{O ESTADO DA QUESTÃO}

A existência de vostê com diversas formas (vostede, vusté, vustede) aparece em todos os dicionários galegos dos séculos XIX e XX antes que a normativa da RAG escolhesse vostede. Se darmos uma vista de olhos aos dicionários galegos recolhidos no Dicionario de dicionários da Universidade de $\mathrm{Vigo}^{2}$, veremos

1 No presente estudo utilizamos as formas do galego internacional. O pronome $t u$ usase grosso modo na metade oriental da Galiza, enquanto $t i$ é utilizado na metade ocidental. A respeito de vostê, na norma RAG é sempre grafado vostede. Este vostê é a forma usual em galego equivalente até certo ponto ao português europeu você que também é utilizada em textos escritos em galego internacional, mas que não existe em galego comum.

2 Disponível em linha<http://sli.uvigo.es/ddd/index.html> 
que todas elas aparecem. Para vostê/vostede há estas ocorrências ${ }^{3}:$ Valladares (1884), Filgueira (1926), Carré (1928-1931), Carré (1933), Ibáñez (1950), Carré (1951), Franco (1972), Carré (1979). Para vustê há também bastantes ocorrências: Aguirre (1858), Rodríguez (1863), Cuveiro (1876), Valladares (1884), Porto (1900c), Acevedo (1932), Rodríguez (1958-1961) e Franco $(1972)^{4}$.

Para além disso, as gramáticas contemporâneas do galego dedicam à questão dos pronomes de cortesia umas poucas linhas. Assim, a RAG nas suas Normas (2012: 88) diz:

As formas de cortesíason vostede e vostedes, que esixen verbo en terceira persoa de singular ou plural, respectivamente. A escolla a favor destas formas vén dada xa pola tradición escrita desde o século XIX. As formas tradicionais, hoxe dificilmente recuperables, eran vós e el (ela, eles, elas), aínda vivas en certas zonas.

A gramática do galego contemporâneo de Freixeiro Mato (2006: 212), provavelmente a mais completa e acurada, fornece pouca informação mais sobre a questão:

Hai restos vivos na fala do antigo uso de el, ela, eles, elas cando non se sabe ben o tratamento que lle dar a unha persoa (El ten moito traballo, bótolle unha man?); é un tratamento intermedio entre o de cortesía (vostede) e o de familiaridade $(t i)$; vós, invariábel, referido a un interlocutor singular ou plural seguindo tamén o uso antigo, tende a desaparecer, reservándose para o trato conpersoas de avanzada idade (Vós chegastes esgotado, non si, avó?). Pode producirse equívoco cando hai máis de un interlocutor (Vós non estadesben de saúde); o verbo vai sempre en segunda persoa de plural.

Existe ainda uma forma de tratamento de respeito, o tio / a tia, que é apenas referida como forma de tratamento sem muitas referências na literatura académica. Freixeiro Mato não fala dela e tão-pouco aparece nas Normas da RAG. Há apenas uma referência no VOLG na voz tío, terceira aceção ${ }^{5}$ :

3. Tratamento de respecto que se lles dá áspersoas de certa idade nalgunhas partes. Isto díxomo o tío Andrés e créolloben. SINÓNIMO SEÑOR

O dicionário Estraviz ${ }^{6}$, o mais completo do galego, tão-pouco dá muita informação:

${ }^{3} \mathrm{http} / / /$ sli.uvigo.es/ddd/ddd_pescuda.php?pescuda=Vost\%E9\&tipo_busca=lema. Acesso em 23 de dez. 2017

${ }^{4}$ http://sli.uvigo.es/ddd/ddd_pescuda.php?pescuda=vust\%E9\&tipo_busca=lema. Acesso em 23 de dez. 2017. Valladares e Franco recolhem as duas formas: vosté e vusté.

5 Disponível em linha < http://academia.gal/dicionario/-/termo/busca/t\%C3\%ADo $>$. Acesso em 22 de dezembro 2017.

6 Disponível em linha <http://www.estraviz.org/tio>. Acesso em 22 de dezembro 2017. 
(3) Tratamento de respeito que se dá nas aldeias aos homens e mulheres de certa idade: teu tio, sem o artigo.

E aqui surge um problema de nomenclatura, visto que «forma de tratamento» pode referir-se quer ao vocativo, quer ao sujeito. No caso da fórmula tio, tem ambos os usos. É vocativo (amiúde sob a forma $t i$ ) em:

(1) Tio, quer cear hoje connosco?

Porém, trata-se de sujeito em:

(2) O tio quer cear hoje connosco?

Trataremos deste caso mais abaixo.

\section{VOSTÊ/VOSTEDE}

É a forma que todos os manuais de galego segundo a norma RAG recolhem como forma de cortesia, mas sob a forma vostede. Na língua falada, contudo, é mais comum vostê, plural vostês. No galego falado não se encontra você, embora esta seja a única forma que recolhe o dicionário Estraviz ${ }^{7}$ e seja a defendida por Costa Casas (1988:91) mesmo dentro do padrão do RAG.

Não há nenhuma dúvida de que a forma galega vostê, bem como a catalã vostè, têm origem na castelhana usted, como demonstrou para o galego J. L. Rodríguez (2000). Quando no século XVI se impõem as formas derivadas de merced em espanhol e mercê em português, o galego e o catalão, por estarem submetidos à influência do espanhol, adaptam a nova forma de cortesia resultante usted < vuessa merced. Em toda a Península Ibérica a forma de cortesia habitual fora vós, originariamente $2 \mathrm{PP}$, que procede do latim vulgar originariamente de uso majestático.

O usted espanhol impor-se-á como forma de cortesia na Galiza lentamente sob a forma vostê, mas não aconteceu tão rápido como nos territórios de língua castelhana e até o século xx teve que coabitar com formas de tratamento locais. Durante o tempo que tem que ganhar o seu espaço e tem de competir com as outras formas de cortesia, o vostê adquire uma etiqueta que na altura podemos definir como [+urbano], de tal maneira que as outras formas de cortesia existentes no idioma são hoje vistas como [-urbano], para além de outros traços sociolinguísticos que definiremos mais abaixo.

A expansão do espanhol vuessa merced $>(v)$ usted chegará além dos territórios ibéricos, visto que com o apoio do catalão chegará até a Sardenha, território com forte influência linguística do espanhol e do próprio catalão por ter

$7<$ http://www.estraviz.org/voc\%C3\%AA> 
pertencido à Coroa de Aragão primeiro e ao Reino de Espanha depois, até ao Acordo de Paz de Utrecht (1713).

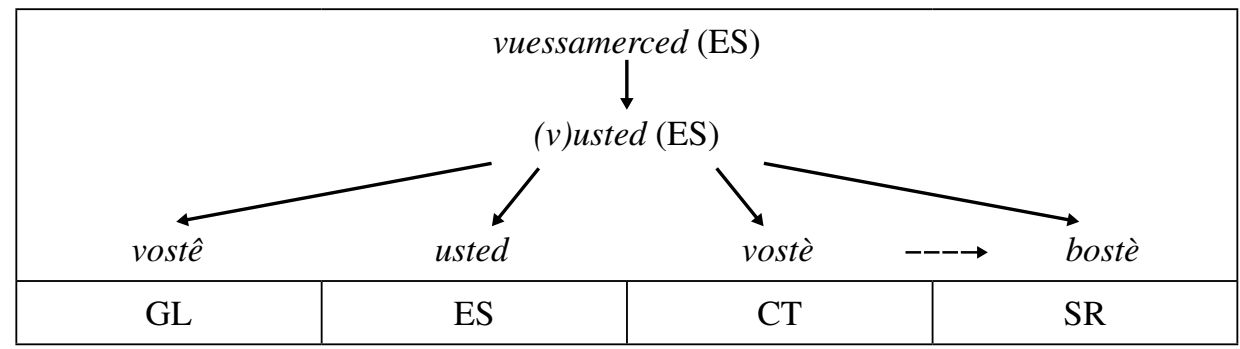

Ora bem, nas três línguas em que a forma castelhana se impôs não desapareceu a antiga forma de cortesia vós. O galego, o catalão e o sardo mantêm a dita forma, de maneira que coabitam dois sistemas de cortesia com caraterísticas muito diferentes do ponto de vista paradigmático.

\section{VÓS}

A forma vós de cortesia tem R 2PS/2PP e П2PP. Em galego, isso envolve que no plural se anula a distinção [+familiar] [-familiar], como acontece em francês com o vous.

Isso provoca muita ambiguidade sobre o valor de cortesia ou a falta dela em exemplos descontextualizados, como:

(3) E vós, já recolhestes o vosso filho da escola?

Neste exemplo, vós pode ter vários valores [ \pm formal]

\begin{tabular}{|l|c|c|c|}
\cline { 2 - 4 } \multicolumn{1}{c|}{ GL } & Dêixis & Referência & Paradigma \\
\hline vós ${ }_{1}$ & {$[+$ FORMAL $]$} & $2 \mathrm{PS}$ & $2 \mathrm{PP}$ \\
\hline vó $s_{2}$ & {$[+$ FORMAL] } & $2 \mathrm{PP}$ & $2 \mathrm{PP}$ \\
\hline vó $s_{3}$ & {$[$-FORMAL] } & $2 \mathrm{PP}$ & $2 \mathrm{PP}$ \\
\hline
\end{tabular}

A ambiguidade do seu uso, junto com a influência do espanhol, fez com que a forma vostê ganhasse terreno, pois permitia distinguir os seus usos claramente:

(4) E vós, já recolhestes o vosso filho da escola?

(5) E vostê, já recolheu o seu filho da escola?

(6) E vostês, já recolhêrom o seu filho da escola? 
Cuja estrutura é respetivamente:

\begin{tabular}{|l|c|c|c|}
\cline { 2 - 4 } \multicolumn{1}{c|}{ GL } & Dêixis & Referência & Paradigma \\
\hline vós & {$[-$ formal $]$} & $2 \mathrm{PP}$ & $2 \mathrm{PP}$ \\
\hline vostê & {$[+$ formal $]$} & $2 \mathrm{PS}$ & $3 \mathrm{PS}$ \\
\hline vostês & {$[+$ formal] } & $2 \mathrm{PP}$ & $3 \mathrm{PP}$ \\
\hline
\end{tabular}

Porém, a entrada do vostê vai terminar com formas intermédias que no galego atual estão em decadência.

No entanto, existe ainda em galego o vós de cortesia, embora se esteja a perder. Usa-se, porém, em zonas do ocidente corunhês (Olmo 2012:145), no Concelho da Fonsagrada em Lugo e no portugalego de Xalma em Cáceres (Frias, 1999). Nestas zonas, encontramos um muito arcaizante, onde o exemplo (3) está em vigência. O sistema, para estas zonas, resulta:

\begin{tabular}{|c|c|c|c|}
\hline GL_Xalma & SG & & PL \\
\hline [-formal] & $t u$ & \multirow{2}{*}[\pm\text{formal}]{} & \multirow{2}{*}{ vós } \\
\hline [+formal] & vós & & \\
\hline
\end{tabular}

De facto, este é o sistema medieval conservado nestas áreas e que se remonta ao latim vulgar ${ }^{8}$. Em catalão, como em galego, a entrada da forma importada do castelhano está a acabar com a forma vos de cortesia. Nesta língua, a criação de uma forma vosaltres (paralela à espanhola vosotros) permitiu distinguir

${ }^{8}$ Como já mencionámos antes, este é ainda o sistema do francês. Responde ao seguinte esquema:

\begin{tabular}{|c|c|c|}
\cline { 2 - 3 } \multicolumn{1}{c|}{} & SG & PL \\
\hline [+formal] & $t u$ & vous \\
\hline$[$-formal] & vous & vous \\
\hline
\end{tabular}

Pela grande influência que teve a língua francesa em Europa, as formas de cortesia de género francês expandiram-se por muitos outros países. Assim, quase todas as línguas eslavas seguem o padrão francês para a formação das formas de cortesia, como por exemplo o checo, o eslovaco ou o russo:

\begin{tabular}{|c|c|c|}
\cline { 2 - 3 } \multicolumn{1}{c|}{ CS-SL } & SG & PL \\
\hline$[+$ +formal $]$ & $t y$ & $v y$ \\
\hline$[$-formal $]$ & $v y$ & $v y$ \\
\hline
\end{tabular}

\begin{tabular}{|c|c|c|}
\cline { 2 - 3 } \multicolumn{1}{c|}{ RU } & SG & PL \\
\hline [+formal] & $m b l$ & $b b l$ \\
\hline$[$-formal] & $b b l$ & $6 b l$ \\
\hline
\end{tabular}


vosaltres [-formal] de vós [+formal]. De facto, no padrão catalão atual mantémse um sistema com duas formas de cortesia:

\begin{tabular}{|l|c|c|c|}
\cline { 2 - 4 } \multicolumn{1}{c|}{} & Dêixis & Referência & Paradigma \\
\hline$t u$ & $\begin{array}{c}{[- \text { FORMAL }]} \\
{[+ \text { COLOQUIAL }]}\end{array}$ & $2 \mathrm{PS}$ & $2 \mathrm{PS}$ \\
\hline vós & $\begin{array}{c}{[+ \text { FORMAL }]} \\
{[- \text { COLOQUIAL }]}\end{array}$ & $\begin{array}{c}2 \mathrm{PS} \\
2 \mathrm{PP}\end{array}$ & $2 \mathrm{PP}$ \\
\hline vostè & $\begin{array}{c}{[+ \text { formal }]} \\
{[+ \text { coloquial }]}\end{array}$ & $2 \mathrm{PS}$ & $3 \mathrm{PS}$ \\
\hline vostès & $\begin{array}{c}{[+ \text { FORMAL }]} \\
{[+ \text { COLOQUIAL }]}\end{array}$ & $2 \mathrm{PP}$ & $3 \mathrm{PP}$ \\
\hline
\end{tabular}

A diferença principal entre vós e vostè(s) encontra-se, portanto, em que a primeira é uma forma hoje apenas administrativa e a segunda é usada na língua corrente. Contudo, na língua padrão também se tencionou manter um sistema de três graus, onde vós estaria entre tu/ vosaltres e vostè( $(s)$ (Lacreu 2002:189190), mas que não calhou na língua falada.

Como já vimos acima, Freixeiro Mato (op. cit.) insiste no valor de vós como forma rural e frequente para se dirigir às pessoas idosas. Achamos que esta última afirmação não é exata, mas trata-se simplesmente da forma de cortesia. Ora bem, a sua redução aos ambientes rurais é recente, deslocada por vostê( $(s)$ como já assinalámos.

É difícil apreciar se o uso de vós aparece como fórmula de cortesia nos dicionários históricos. EmRodríguez (1958-61: s.v.) diz: «Pronombre personal de segunda persona en género masculino y femenino y número singular y plural: Non vos digo que non; non vos fan caso» [negrito nosso], que poderia ser interpretado que, com efeito, se trata de uma forma de cortesia por falar do seu uso tanto no singular quanto no plural. A sua definição é copiada por Franco Grande (1972: s.v.) até com os mesmos exemplos.

Este uso do vós em galego é uma forma de cortesia, mas em nenhum caso é um uso equivalente ao voseio do espanhol americano.

\section{5. $\operatorname{ELE}(\mathrm{S}), \operatorname{ELA}(\mathrm{S})$}

O uso de ele como pronome de cortesia também tende a desaparecer em galego, pois é considerado uma forma rural, como tio/a, mas não é exclusiva da Galiza. Zamora Vicente (1967: 203) recolhe-a em asturo-leonês e judeuespanhol (id. 283), chegando mesmo a terras de Ávila ainda no século xx. Mais recentemente, é documentada no sendinês (Merlan 2010: 228)

Este uso de ele tem certo paralelismo com a forma portuguesa europeia de uso do nome próprio como forma de tratamento, como em: 
(7) A Maria ${ }^{9}$ vai tomar o café connosco?

Este exemplo fica à metade entre:

(8) (Tu) vais tomar o café connosco?

(9) (Você) vai tomar o café connosco?

(10) A senhora vai tomar o café connosco?

Estes quatro níveis próprios do português europeu requerem uma complexidade maior de etiquetas para a sua dêixis:

\begin{tabular}{|c|c|c|c|}
\hline PT_EU & Dêixis & Referência & Paradigma \\
\hline$t u$ & $\begin{array}{c}{[- \text { FORMAL }]} \\
{[\text {-RESPEITO }]} \\
{[+ \text { CONHECIDO }]}\end{array}$ & $2 \mathrm{PS}$ & $2 \mathrm{PS}$ \\
\hline (nome próprio) & $\begin{array}{c}{[\text {-FORMAL }]} \\
{[+ \text { RESPEITO }]} \\
\text { [+CONHECIDO }]\end{array}$ & 2PS & 3PS \\
\hline você & $\begin{array}{c}\text { [+FORMAL] } \\
\text { [+RESPEITO] } \\
\text { [+CONHECIDO] }\end{array}$ & 2PS & 3PS \\
\hline a senhora & $\begin{array}{c}{[+ \text { FORMAL }]} \\
{[+ \text { RESPEITO }]} \\
{[- \text { CONHECIDO }]}\end{array}$ & 2PS & 3PS \\
\hline
\end{tabular}

No caso galego são apenas três, com uma dêixis mais simple:

\begin{tabular}{|c|c|c|c|}
\cline { 2 - 4 } \multicolumn{1}{c|}{ GL } & Dêixis & Referência & Paradigma \\
\hline$t u$ & $\begin{array}{r}{[\text { [-FORMAL] }} \\
{[- \text { RESPEITO }]}\end{array}$ & $2 \mathrm{PS}$ & $2 \mathrm{PS}$ \\
\hline ele $/$ ela & $\begin{array}{r}{[- \text { FORMAL] }} \\
{[+ \text { RESPEITO }]}\end{array}$ & $2 \mathrm{PS}$ & $3 \mathrm{PS}$ \\
\hline vostê & $\begin{array}{r}{[+ \text { FORMAL] }} \\
{[+\mathrm{RESPEITO}]}\end{array}$ & $2 \mathrm{PS}$ & $3 \mathrm{PS}$ \\
\hline
\end{tabular}

${ }^{9} \mathrm{O}$ uso de um SN, que como nome próprio,quer como nome comum, em função de sujeito e com valor de forma de tratamento é chamado por nós pronominalização espontânea. Em português europeu é feito com o nome próprio, mas no espanhol de Bogotá, por exemplo, é habitual com a profissão: ¿El profe se viene a tomar café connosotros? 
Existe uma diferença importante entre sistema galego e o português europeu. No primeiro caso, trata-se de um sistema compensado entre singular e plural, enquanto no segundo é descompensado:

\begin{tabular}{|c|c|c|c|c|}
\hline GL & \multicolumn{2}{|c|}{ SG } & \multicolumn{2}{|c|}{ PL } \\
\hline $\begin{array}{c}{[\text {-FORMAL }]} \\
{[- \text { RESPEITO }]}\end{array}$ & \multicolumn{2}{|c|}{$t u$} & \multicolumn{2}{|c|}{ vós } \\
\hline $\begin{array}{c}{[\text {-FORMAL }]} \\
{[+ \text { RESPEITO }]}\end{array}$ & ele & ela & eles & ela \\
\hline $\begin{array}{c}\text { [+FORMAL] } \\
\text { [+RESPEITO] }\end{array}$ & \multicolumn{2}{|c|}{ vostê } & \multicolumn{2}{|c|}{ vostês } \\
\hline
\end{tabular}

\begin{tabular}{|c|c|c|c|}
\hline PT_EU & SG & & PL \\
\hline $\begin{array}{c}{[- \text { FORMAL }]} \\
{[\text {-RESPEITO }]} \\
{[+ \text { CONHECIDO }]}\end{array}$ & $t u$ & \multirow{3}{*}{$\begin{array}{c}{[ \pm \text { FORMAL }]} \\
{[ \pm \text { RESPEITO }]} \\
{[ \pm \text { CONHECIDO }]}\end{array}$} & \multirow{3}{*}{ vocês } \\
\hline $\begin{array}{c}\text { [-FORMAL] } \\
\text { [+RESPEITO }] \\
\text { [+CONHECIDO }]\end{array}$ & $\mathrm{SN}$ & & \\
\hline $\begin{array}{c}\text { [+FORMAL }] \\
{[+ \text { RESPEITO }]} \\
{[+ \text { CONHECIDO }]}\end{array}$ & você & & \\
\hline $\begin{array}{c}{[+ \text { FORMAL }]} \\
{[+ \text { RESPEITO }]} \\
{[- \text { CONHECIDO }]}\end{array}$ & a senhora & $\begin{array}{c}{[+ \text { FORMAL }]} \\
{[+ \text { RESPEITO }]} \\
{[- \text { CONHECIDO }]}\end{array}$ & as senhoras \\
\hline
\end{tabular}

Contudo, o sistema atual tende a eliminação desta forma intermédia para ficar reduzido a um sistema de dois graus:

\begin{tabular}{|c|c|c|}
\cline { 2 - 3 } \multicolumn{1}{c|}{ GL } & SG & PL \\
\hline$[$-FORMAL] & $t u$ & vós \\
\hline [+FORMAL] & vostê & vostês \\
\hline
\end{tabular}

Este sistema é idêntico ao do espanhol padrão europeu e não cabe dúvida que a influência da língua castelhana foi imensa para a sua fixação. 


\section{6. $\quad$ O TIO A TIA}

Finalmente, a última das formas que nos interessa tratar como de tratamento é o SN o tio com a sua correspondente forma feminina a tia. Neste caso, trata-se também de uma forma que existe em português e que também se reduz aos ambientes rurais, «às aldeias». Eu próprio tenho ouvido esta forma ainda nesta década em Trás-os-Montes.

A forma o tio latia está ainda mais estendida na Galiza como vocativo. Provavelmente do seu uso como vocativo passou para o seu uso como sujeito. É também muito complicado seguir o rasto do seu uso como forma de tratamento nos dicionários, os quais, por norma, se referem a ela como um «tratamento de respeito» para se dirigir a uma pessoa idosa, como faz o Estraviz (s.v.) e também o resto de dicionários históricos (Rodríguez 1958-61; Franco 1972; Carré 1979: s.v.)

Há também um notável paralelismo, pelo menos em português, como o desenvolvimento do sintagma o senhor/a senhora que se gramaticalizou até se tornar uma forma de cortesia. De facto, as formas de cortesia são em muitos casos processos de gramaticalização, que podem ficar no primeiro estádio - $\mathrm{O}$ $\mathrm{SN}$, como em o senhor, o tio, a gente (PT_BR)—, ou alcançar um segundo nível e pronominalizar-se, como você (<vossa mercê).

Já acima mencionámos que sendo $o$ tio uma forma de tratamento de vocativo, passo a ser utilizado como sujeito como gramaticalização do SN. Ambos os usos vivem juntos ainda em todo o domínio portugalego europeu em âmbitos rurais, como já foi dito, mas interessa ver qual o processo de gramaticalização.

Foi primeiro o vocativo, como em:

(11) Ó ti $(o)^{10}$, pro quer vir almorçar connosco na casa?

Daí passou para o sujeito, para o qual requereu do artigo

(12) O tio quer vir almorçar connosco na casa?

Sintaticamente, a frase 11 é representada assim:

\begin{tabular}{|c|c|c|c|}
\hline VOC & SUBJ & PRED & OBJ \\
\hline Ó ti $(o)$ & pro & quer & almorçar connosco na casa? \\
\hline
\end{tabular}

\begin{tabular}{|c|c|c|c|}
\hline VOC & SUBJ & PRED & OBJ \\
\hline Fit(o) & O tio & quer & almorçar connosco na casa? \\
\hline
\end{tabular}

${ }^{10}$ A redução de tio e tia para ti nas formas de tratamento é muito frequente em todo o galego. 


\section{O PROCESSO DE FORMAÇÃO DAS FORMAS DE CORTESIA EM GALEGO}

Fora do portugalego, existem mostras de gramaticalização das formas de cortesia em toda a parte, como por exemplo o polaco pan (fem. pani), que de facto significam [o] senhor e [a] senhora respetivamente, com um paradigma de terceira pessoa. A mesma situação encontra-se no árabe egípcio, que desenvolveu uma forma de cortesia inexistente no árabe clássico, através de حضرتك , que é também um SN, embora com um sufixo possessivo.

Este processo ajuda a entender como funciona o processo de criação das formas de tratamento. Dentro do galego, teríamos as seguintes fases:

1. Uso do plural para expressar a cortesia em singular

2. Uso da 3P para expressar a cortesia na $2 \mathrm{P}$

3. Substituição de um pronome por um SN que se gramaticaliza

4. Gramaticalização do SN que pronominaliza

\begin{tabular}{|c|c|c|c|c|c|}
\hline \multirow{2}{*}{ GL } & \multirow{2}{*}{ [-formal] } & \multicolumn{4}{|c|}{ [+formal] } \\
\hline & & SG $>$ PL & $2 P>3 P$ & PRN $>$ SN & SN $>$ PRN \\
\hline Proto-romance & \multirow[t]{5}{*}{$t u / t i$} & \multirow[t]{5}{*}{ vos } & & & \\
\hline Medievo & & & \multirow[t]{4}{*}{ ele, ela } & & \\
\hline & & & & o t10, a tia & \\
\hline S. XVII & & & & & \multirow[t]{2}{*}{ vostê } \\
\hline S. XXI & & & & ! & \\
\hline
\end{tabular}

\section{A ETIQUETAGEM DAS FORMAS DE TRATAMENTO GALEGAS}

À vista das quatro formas de cortesia apresentadas no gráfico anterior, é preciso caraterizá-las com etiquetas, pois até podem coabitar várias delas num mesmo território e serem usadas pelo menos três delas por um mesmo falante. Para além das etiquetas habituais de [ \pm formal], é preciso apresentar mais algumas que expliquem as diferenças de uso do ponto de vista pragmático e sociolinguístico.

$\mathrm{Na}$ seguinte tabela apresentamos todas as formas apresentadas até agora para o galego 


\begin{tabular}{|c|c|c|c|}
\hline GL & Dêixis (G. $\left.{ }^{\circ}\right)$ & $\mathbf{R}$ & II \\
\hline tu & [-FORMAL] [-IDADE] [-RURAL] [+PRÓXIMO] & 2PS & 2PS \\
\hline ele, ela & [-FORMAL] [-IDADE] [-RURAL] [-PRÓXIMO] & 2PS & 3PS \\
\hline vós $s_{1}$ & [+FORMAL] [+IDADE][-RURAL] [-PRÓXIMO] & 2PS & $2 \mathrm{PP}$ \\
\hline o tio, a tia & [+FORMAL] [+IDADE] [+RURAL] [-PRÓXIMO] & 2PS & 3PS \\
\hline vostê & [+formal] [-idade] [-rural] [-próximo] & 2PS & 3PS \\
\hline vós $s_{2}$ & [-FORMAL] [-IDADE] [-RURAL] [+PRÓXIMO] & $2 \mathrm{PP}$ & $2 \mathrm{PP}$ \\
\hline eles, elas & [-FORMAL] [-IDADE] [-RURAL] [-PRÓXIMO] & $2 \mathrm{PP}$ & $3 \mathrm{PP}$ \\
\hline vós ${ }_{3}$ & [+FORMAL] [+IDADE][-RURAL] [-PRÓXIMO] & $2 \mathrm{PP}$ & $2 \mathrm{PP}$ \\
\hline $\begin{array}{l}\text { os tios, as } \\
\text { tias }\end{array}$ & [+FORMAL] [+IDADE] [+RURAL] [-PRÓXIMO] & $2 \mathrm{PP}$ & $3 \mathrm{PP}$ \\
\hline vostês & [+FORMAL] [-IDADE] [-RURAL] [-PRÓXIMO] & $2 \mathrm{PP}$ & $3 \mathrm{PP}$ \\
\hline
\end{tabular}

No portugalego de Xalma, o vós de cortesia, é, como já foi dito, a única forma de cortesia e não tem de ser contrastada com outras formas formais.

Porém, a tabela anterior não define completamente a riqueza das formas de tratamento. Até cá temos falado em paradigmas (П) só para nos referir aos paradigmas verbais. Porém, os paradigmas que afetam às formas de tratamento referem-se também aos clíticos e aos possessivos. Estes são elementos cruciais que devem ser estudados para compreender a natureza das formas de tratamento em galego ou em qualquer idioma. Portanto, quando falamos em 3PS ou 2PS para os verbos, é isso também extensível aos clíticos e possessivos? No caso do galego, sim. Para além de tu e vós, o resto das formas seguem o paradigma da 3P também quanto aos clíticos e os possessivos.

Porém, não é sempre assim noutras partes do portugalego, existemalgumas exceções. A primeira encontramo-la no português do Brasil, onde com você (П verbal de $3 \mathrm{P}$ ) pode aparecer opcionalmente um clítico te (2PS) e um possessivo teu $(2 \mathrm{PP})$ :

(13) Você (П3PS) pegou teu (П2PS) livro?

Também é assim com a gente, (П verbal de 3PS, R de 1PP), com o qual é possível usar o possessivo nosso (П 1PP):

(14) A gente(П3PS) não fez nosso(П1PP) dever 
No português padrão de Portugal as coisas são muito mais confusas com a forma vocês. Deu-se uma mistura dos paradigmas pronominais de vós e vocês até se fundirem. Vejam-se os seguintes exemplos:

(15) Vocês (П3PP) trouxeram (П 3PP) os vossos (П 2PP) vestidos?

(16) Vocês (П3PР) lembraram-se (П3PP) disso?

(17) Pediram-me para vos (П 2PP) guiar pela cidade.

(18) Ninguém se lembra de vós (П 2PP) /vocês (ПЗPP).

(19) Ficarei um bocadinho cá convosco (П 2PP) / com vocês (П3PP).

\section{CONCLUSÕES}

O sistema das formas de tratamento galego é muito mais complexo do que aparenta. Neste estudo não aprofundámos nos usos pragmáticos e sociais que tềm cada uma delas. Portanto, não nos aproximámos da realidade do uso das formas de cortesia na fala real hodierna. Embora seja evidente que o uso de $t u / t i$ avança em galego, é preciso fazer estudos que visem entender qual o alcance da mudança dos usos linguísticos. Cá contentámo-nos com apresentar as formas próprias do galego, vendo que muitas delas existem, seja no próprio diassistema (por exemplo, o uso de o tio/a tia) em Portugal, seja nos domínios vizinhos (por exemplo o uso de ele, ela em asturo-leonês e até em espanhol ibérico).

Foi preciso estabelecer novas etiquetas para individualizar cada uma das formas ditas de cortesia, porque o uso de ele/a é distinto do uso de o tio/a tia. O sistema de etiquetagem que utilizamos serve bem para estes propósitos, embora, como já indicámos, fica muito caminho a percorrer.

Infelizmente, temos também que constatar que todos os sistemas e subsistemas de formas de tratamento que historicamente teve o galego ficam reduzidos a dias de hoje a um sistema que é um decalque do espanhol. Apenas as formas $t u / t i$, vós e vostê sobrevivem e são as que fazem parte do sistema de tratamento da imensa maioria dos falantes de galego, enquanto ele/a, o tiola tia e o vós de cortesia são já desconhecidos para a maioria dos falantes mais novos.

É preciso também salientar que a forma de cortesia historicamente mais neutra do ponto de vista pragmático em galego, mesmo ainda até o século $\mathrm{xx}$, antes da generalização de vostês foi vós, conservada em ilhós no território de língua galega e no enclave de Xalma em Cáceres. Assim o demostra o seu uso na poesia de Rosalia de Castro nos seus Cantares Gallegos, 124: 


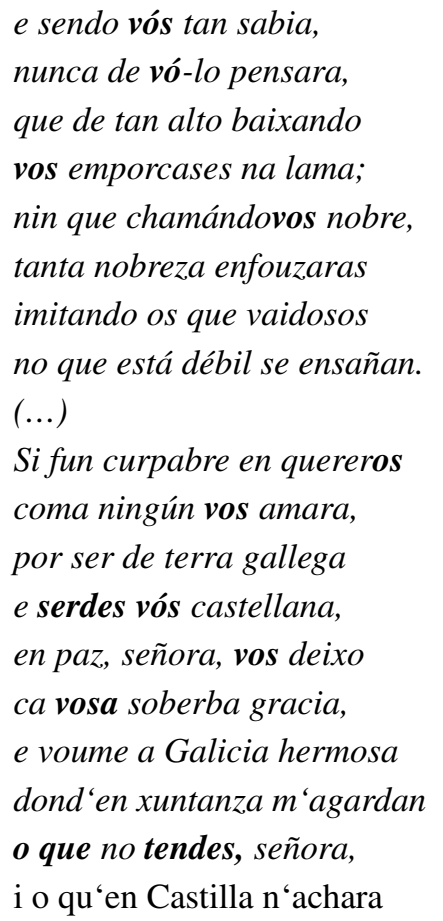

\section{BIBLIOGRAFIA}

Acevedo y Huelves,B + Fernández y Fernández, M. (1932) Vocabulario del bable de occidente, Oviedo.

AguirredelRío, L. (1858) Diccionario del dialecto gallego, ed. de Carme Hermida Gulías, CSIC-IPS, 2007

Calvo del Olmo, F. J. (2011) «Sobre la gramaticalización de los tratamientosnominalesen las lenguas românicas: paralelismos e influencias», Caligrama, Revista de Estudos Românicos 16-2, pp. 131-153. Disponível em linha. <http://www.periodicos.letras.ufmg.br/index.php/caligrama/article/ view/1622>. Acesso em: $22 \mathrm{dez} .2017$.

Carré Alvarellos, L. (1928-1931) Diccionario galego-castelán, 1. ${ }^{a}$ ed., Lar, A Cruña, 1926-1931

Carré Alvarellos, L. (1933) Diccionario galego-castelán, Segunda Edizón, A Coruña, Roel

Carré Alvarellos, L. (1951) Diccionario galego-castelán, Terceira Edizón, A Coruña, Roel

Carré Alvarellos, L. (1979) Diccionario galego-castelán e Vocabulario castelán-galego, A Coruña, Moret 
Costa Casas, X.X. etalii (1988) Nova gramática para a aprendizaxe da língua, Corunha, Via Láctea.

Cuveiro Piñol, J. (1876) Diccionario Gallego, Barcelona

Estraviz, I. (s/d). Dicionário Estraviz, em linha: <www.estraviz.org>

Fernández Rodríguez, M. (2003) «Constitución del orden social y desasosiego: pronombres de segunda persona y fórmulas de tratamiento en español», Pronombres de segunda persona y formas de tratamiento en las lenguas de Europa. Coloquio de París. CVC. Disponível em linha: <https://cvc.cervantes.es/lengua/coloquio_paris/ponencias/pdf/cvc_fernandez.pdf $>$ Acesso em: 22 de dez. 2017.

Filgueira Valverde, X + Tobío Fernandes, L. + Magariños Negreira A e Cordal Carús, X. (1926) Vocabulario popular castelán-galego (publicado por entregas en El Pueblo Gallego)

Franco Grande, X.L. (1972) Diccionario galego-castelán, 2. ${ }^{a}$ ed., Galaxia, Vigo.

Freixeiro Mato, X.R. (2006) Gramática da Lingua Galega. II Morfosintaxe, Vigo, Promocións Culturais Galegas.

Frias Conde, X + Uruburu Rodríguez, M. (2017) Las formas de tratamento, Toledo, Ianua Ed.

Frias Conde, X. (1999) O galego exterior às fronteiras administrativas, VTP, Gijón.

Frias Conde, X. (2011) «Revisitando o sistema dos pronomes de cortesia no diassistema galego-português», RLLCGV, XVI, pp. 113-124.

Ibáñez Fernández, J. (1950) Diccionario galego da rima e galego-castelán, Madrid

ILG (s/d) Dicionario de dicionário, disponível em <http://sli.uvigo.es/ddd/ index.html>

ILG /RAG (2012) Normas ortográficas e morfolóxicas do idioma galego, Vigo, Galaxia.

Lacreu, J. (2002): Manual d'ús de l'enstàndard oral, València, Universitat de València.

Merlan, A. (2010) «Sistemas de tratamientoen variedades astur-leonesas», Homenaxe al professor XoséLluis Garcia Arias, tomo I, ALLA, Oviedo, pp. $217-242$

Pintos Villar, J.M. (1865) Vocabulariogallego-castellano, ed. de Margarita Neira e XesúsRiveiro, A Coruña, RAG, 2000

Porto Rey, F. (1900) Diccionario gallego-castellano, ed. de María Xesús Bugarín e Begoña González Rei, A Coruña, Real Academia Galega, 2000

Rodríguez González, E. (1958-1961) Diccionario enciclopédico gallego-castellano, Galaxia, Vigo 
Rodríguez, F. J. (1863) Diccionario gallego-castellano, ed. de Antonio de la Iglesia González, A Coruña

Rodríguez, J.L. (2000): «Para um perfil das formas de tratamento: vostede/vostê... você», Estudos dedicados a Carvalho Calero, I, Linguística. pp. 847883.

ValladaresNúñez, M. (1884) Diccionariogallego-castellano, Santiago, Imp. Seminario Conciliar

Zamora Vicente, A. (1970) Dialectología española, Madrid, Gredos. 